\title{
Papers
}

\section{State income inequality, household income, and maternal mental and physical health: cross sectional national survey}

\author{
Robert S Kahn, Paul H Wise, Bruce P Kennedy, Ichiro Kawachi
}

\begin{abstract}
Objective To examine the association of state income inequality and individual household income with the mental and physical health of women with young children.

Design Cross sectional study. Individual level data (outcomes, income, and other sociodemographic covariates) from a 1991 follow up survey of a birth cohort established in 1988. State level income inequality calculated from the income distribution of each state from 1990 US census.

Setting United States, 1991.

Participants Nationally representative stratified random sample of 8060 women who gave birth in 1988 and were successfully contacted (89\%) in 1991. Main outcome measures Depressive symptoms (Center for Epidemiologic Studies depression score $>15)$ and self rated health

Results 19\% of women reported depressive symptoms, and 7.5\% reported fair or poor health. Compared with women in the highest fifth of distribution of household income, women in the lowest fifth were more likely to report depressive symptoms $(33 \% v 9 \%, \mathrm{P}<0.001)$ and fair or poor health $(15 \% v 2 \%, \mathrm{P}<0.001)$. Compared with low income women in states with low income inequality, low income women in states with high income inequality had a higher risk of depressive symptoms (odds ratio 1.6, 95\% confidence interval 1.0 to 2.6) and fair or poor health (1.8, 0.9 to 3.5).

Conclusions High income inequality confers an increased risk of poor mental and physical health, particularly among the poorest women. Both income inequality and household income are important for health in this population.
\end{abstract}

\section{Introduction}

While the importance of socioeconomic status for health is well documented, ${ }^{12}$ several recent studies suggest that the relative distribution of income within a society is also an important determinant of health. ${ }^{3-7}$ Large inequalities in income between the rich and the poor correlate with lower overall life expectancy and higher total age specific and cause specific mortality, even after adjustment for absolute income differences among the 50 US states. ${ }^{3-6}$ Explanations for the association include the possibility that increased income inequality is associated with a society's lack of investment in social goods such as public education and accessible health care. This underinvestment, in turn, is associated with poor health outcomes. ${ }^{89}$ Alternatively, or perhaps in addition, wider disparities in income may be associated with the erosion of social cohesion within communities, leading to increased risk of social isolation, stress and, ultimately, poor health outcomes. ${ }^{89}$ Given US projections that the income after tax in the richest fifth of households rose by $43 \%$ from 1977 to 1999 while that of the bottom fifth fell $9 \%,{ }^{10}$ the potential health impact of income inequality warrants further evaluation. The need is further underscored by the fact that the United States has among the highest levels of income inequality of any industrialised nation. ${ }^{11}$

Three important gaps remain in our understanding of the relation between income inequality and health. Firstly, concern remains that the effects of income inequality evident in studies that used aggregated or ecological data are simply an artefact of an underlying relation between individual income and health. ${ }^{12}$ The four studies with the ecological and individual level income data necessary to examine this concern have shown mixed results. ${ }^{8}{ }^{13-15}$ One study found that individual income could account entirely for the mortality effects attributed to income inequality ${ }^{13}$ Others have found that an adverse effect of income inequality on self rated health persisted after adjustment for individual income. ${ }^{14}{ }^{15}$ Secondly, among these multilevel studies, only two examined potential interactions between individual income and income inequality. Daly et al found a negative effect of income inequality on mortality only for middle income individuals, ${ }^{8}$ while Kennedy et al found that the adverse effect of income inequality on self rated health diminished with rising individual income. ${ }^{14}$ Determining whether the adverse health effects of income inequality are the same for individuals with high and low income is critical for understanding the mechanisms at work. Finally, while many have hypothesised that income inequality operates via psychosocial processes, there have been no studies using individual level data to examine mental health outcomes.

We examined the joint effects of state income inequality and individual household income on maternal mental and physical health to examine whether women with low household income are most Division of General
and Community
Pediatrics,
Children's Hospital
Medical Center,
CH-1, 3333 Burnet
Avenue, Cincinnati,
OH 45229, USA website 
vulnerable to high income inequality. We focused on women with young children as they tend to be a population particularly vulnerable to state economic and social welfare policy. ${ }^{16}{ }^{17}$

\section{Methods}

\section{Sources of data}

The data used in this analysis are from the 1991 longitudinal follow up to the 1988 National Maternal Infant Health Survey. The 1988 study was a national, population based, stratified random sample of 9953 women who gave birth to live babies in 1988. The stratified design oversampled black infants and very low and low birthweight infants. In 1991, 8285 women (89\%) with children aged 26 to 48 months were successfully reinterviewed in the longitudinal follow up survey. This analysis used data from the 8060 women whose children still lived with them.

\section{Outcome measures of maternal morbidity}

Symptoms of depression and self reported health were used as measures of maternal morbidity. Depressive symptoms were measured with the Center for Epidemiologic Studies Depression scale. Twenty questions determine how many days in the past week a respondent felt each of a range of positive and negative symptoms. A summary score of 16 or higher is correlated with the presence of clinical depression. ${ }^{18}$

Table 1 Sociodemographic and health characteristics of nationally representative sample of US women who gave birth in 1988

\begin{tabular}{|c|c|c|c|c|}
\hline Variable & No of women & Weighted \% & $\begin{array}{c}\text { Depressive } \\
\text { symptoms } \\
\text { (weighted \%) }\end{array}$ & $\begin{array}{c}\text { Fair or } \\
\text { poor health } \\
\text { (weighted \%) }\end{array}$ \\
\hline \multicolumn{5}{|l|}{ Maternal age (years): } \\
\hline $15-19$ & 1254 & 12.0 & $28.2^{\star \star \star}$ & $9.8^{*}$ \\
\hline $20-29$ & 4605 & 59.1 & 19.8 & 7.9 \\
\hline$\geqslant 30$ & 2150 & 28.9 & 13.8 & 5.8 \\
\hline \multicolumn{5}{|l|}{ Marital status: } \\
\hline Married & 4588 & 73.2 & $14.2^{\star \star \star *}$ & $5.9^{\star \star \star}$ \\
\hline Divorced, separated, widowed & 993 & 11.1 & 28.4 & 10.9 \\
\hline Never married & 2279 & 15.7 & 28.1 & 12.8 \\
\hline \multicolumn{5}{|l|}{ Education: } \\
\hline Less than high school graduate & 1643 & 17.5 & $33.1^{\star * \star}$ & $18.0^{\star \star \star *}$ \\
\hline High school graduate/GED & 3093 & 36.9 & 21.8 & 7.9 \\
\hline Beyond high school & 3273 & 45.6 & 11.5 & 3.3 \\
\hline \multicolumn{5}{|l|}{ Race/ethnicity: } \\
\hline White, non-Hispanic & 3355 & 70.8 & $15.4^{\star \star \star}$ & $4.9^{* * *}$ \\
\hline Black, non-Hispanic & 3763 & 16.9 & 28.9 & 12.2 \\
\hline Hispanic & 657 & 12.3 & 23.0 & 16.3 \\
\hline \multicolumn{5}{|l|}{ Fifths of income distribution: } \\
\hline Lowest & 2366 & 19.0 & $33.4^{\star \star \star}$ & $14.9^{* \star \star}$ \\
\hline 2 & 1628 & 19.1 & 26.3 & 11.3 \\
\hline 3 & 1700 & 24.9 & 15.6 & 6.3 \\
\hline 4 & 1142 & 17.7 & 11.7 & 3.8 \\
\hline Highest & 1173 & 19.4 & 9.2 & 2.1 \\
\hline \multicolumn{5}{|l|}{ Income inequality: } \\
\hline High (Gini >0.430) & 4738 & 56.0 & $20.3^{\star \star \star}$ & $8.5^{*}$ \\
\hline Medium (Gini 0.416-0.430) & 2200 & 27.6 & 19.2 & 6.3 \\
\hline Low (Gini $\leqslant 0.415)$ & 1071 & 16.4 & 14.5 & 6.5 \\
\hline \multicolumn{5}{|l|}{ Depressive symptoms: } \\
\hline CES-D $<16$ & 6175 & 80.9 & - & - \\
\hline $\mathrm{CES}-\mathrm{D} \geqslant 16$ & 1834 & 19.1 & - & - \\
\hline \multicolumn{5}{|l|}{ Self rated health: } \\
\hline Excellent, very good, good & 7108 & 92.5 & - & - \\
\hline Fair, poor & 781 & 7.5 & - & - \\
\hline
\end{tabular}

${ }^{*} \mathrm{P}<0.05,{ }^{* * *} \mathrm{P}<0.001$ Source: National Center for Health Statistics, 1991 longitudinal follow up to the 1988 National Maternal and Infant Health Survey.
Maternal self report of health status was determined in response to the question "In general, would you say your health is excellent, very good, good, fair, or poor?" For this analysis, we collapsed maternal general health status to form a dichotomous variable $(0=$ excellent, very good, good; $1=$ fair, poor.) Previous work has shown self reported health status to be highly predictive of mortality, independent of health behaviours, comorbid conditions, and access to health care. ${ }^{19}$

\section{Independent variables}

We used the Gini coefficient derived from the Lorenz curve of household income within a state to measure income distribution. The Lorenz curve plots the cumulative share of income held by the cumulative tenths of households ranked from the poorest to the most affluent. If each successive $10 \%$ of households held $10 \%$ of total income, then the curve would be a diagonal line at $45^{\circ}$. The greater the income disparity between tenths of households, the greater the bowing of the curve away from the diagonal line and the higher the Gini coefficient. The Gini coefficient ranges theoretically from 0.0 (perfect equality) to 1.0 (perfect inequality). The coefficient for each of the fifty states was calculated from data in the 1990 United States census population and housing summary tape file $3 \mathrm{~A}$. As some states surveyed only a limited number of women, we grouped states into approximate thirds of "low," "medium," or "high" inequality (see table w1 on the BMJ's website). Each woman was assigned a categorical value based on her state of residence. Annual household income reported by the survey respondents was categorised into fifths (\$10 000, 10-19 999, 20-34 999, 35-49 999, $>50000)$. Covariates included categorical variables for age ( $<20,20-29, \geqslant 30$ years), marital status (never married, married, divorced/separated), education (below high school degree, high school degree, above high school degree), race/ethnicity (non-Hispanic white, non-Hispanic black, Hispanic), and the number of people living in the household.

\section{Analysis}

Initial bivariate analyses examined the associations between maternal morbidity and state income inequality, individual income, race/ethnicity, education, and marital status. The independent contributions of these variables were then determined in multivariate logistic regression analyses. Given our hypothesis that the effect of income disparity would vary by individual income, the multivariate analyses were stratified and run separately for each income group.

As noted, the survey oversampled certain subgroups to enhance the precision of the estimates related to these populations. Disproportionate selection probability in such stratified sampling can result in increased standard errors. ${ }^{20}$ All analyses used the survey data analysis software, SUDAAN (version 7.5.3, Research Triangle Institute, NC), which accounts for these potential design effects. We also used weights provided by the National Center for Health Statistics to ensure that estimates represented the US distribution of women who gave birth to live babies in 1988. The weights factor in the probability of selection in the stratified design and adjust for potential non-response bias. Though the data combined state level (Gini coefficient) and individual level information, regression analyses used a one level rather than a two level model 


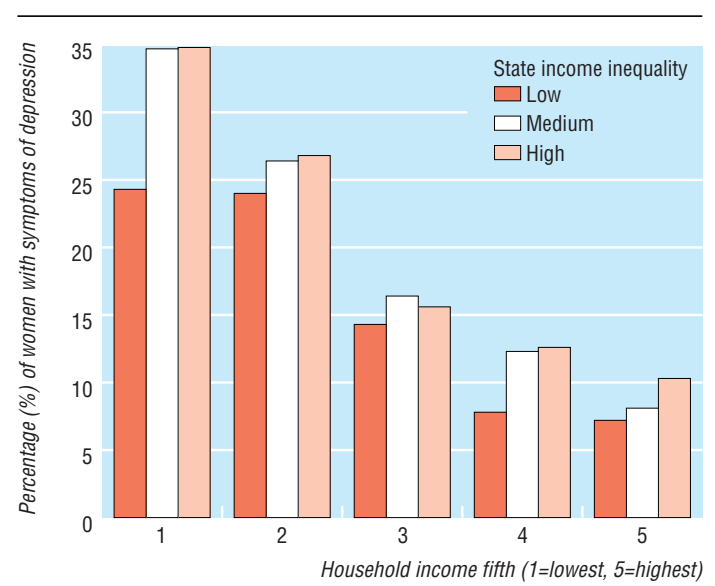

Fig 1 State income inequality, household income, and maternal depressive symptoms. Effect of income inequality significant $(P<0.05)$ only in lowest fifth of household income

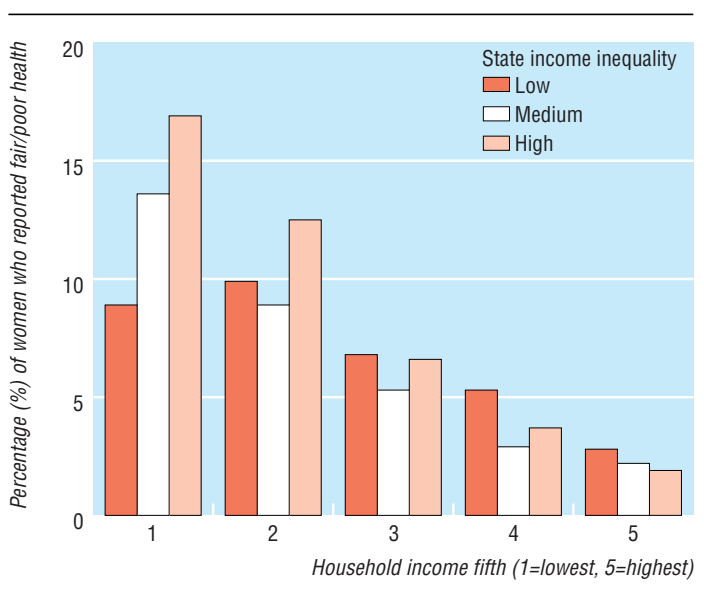

Fig 2 State income inequality, household income, and self reported maternal health. Effect of income inequality significant $(P<0.05)$ only in lowest fifth of household income

because the survey was designed as a national probability sample of individuals not as a two stage sample of states and individuals.

\section{Results}

Table 1 shows the demographic and health characteristics of a nationally representative sample of women who gave birth in 1988. About $19 \%$ of women had symptoms of depression and $7.5 \%$ of women reported themselves as in fair or poor health. Women who were young, unmarried, less educated, or not white were significantly more likely to have symptoms of depression and to rate themselves as in fair or poor health. A strong gradient was found between lower income and both depressive symptoms and fair or poor health. Women living in states with high income inequality were somewhat more likely to report worse mental and physical health.

Figures 1 and 2 show the associations of fifth of household income and state income inequality with the two maternal outcomes. Compared with women with low income living in more egalitarian states, those living in high inequality states were significantly worse off in terms of depressive symptoms $(34.8 \% v 24.3 \%$, $\mathrm{P}<0.05)$ and self rated health $(16.9 \% v 8.9 \%, \mathrm{P}<0.05)$.

We used multivariate models to determine the independent associations of household income and income inequality with maternal health, adjusted for other individual level sociodemographic factors, including race/ethnicity, education, marital status, age, and household size (table 2). The three models presented respond to the common critique that household income and demographic characteristics probably confound estimates of the effects of income inequality. Model 1 is the effect of income inequality alone, model 2 estimates the effect of state income inequality independent of individual income and vice versa, and model 3 estimates their independent effects adjusted for other key sociodemographic characteristics. The estimates of the association between income inequality and both maternal health outcomes were modestly attenuated by the addition of individual income to the models. Full adjustment for covariates further attenuated the odds ratios, though income inequality remained a significant negative predictor of depressive symptoms.

The effects of income inequality stratified by household income were also examined. Among the poorest women, both high and medium income inequality were associated with an increased risk of depressive symptoms (table 3). A similar relation was observed between income inequality and fair or poor health, though this association was not significant. High income inequality was most strongly associated with depressive symptoms (odds ratio 2.3, 95\% confidence interval 1.2 to 4.4 ) and fair or poor health (2.4, 1.0 to 5.8) among women in the lowest tenth of income distribution.

To estimate the joint association of income inequality and household income, the reference group used was women in the top fifth of income distribution who were living in states with low income inequality.

Table 2 State income inequality, household income, and risk of depressive symptoms and fair/poor health. Figures are odds ratios ( $95 \%$ confidence intervals)

\begin{tabular}{lccc}
\multicolumn{1}{l}{ Model 1 } & Model 2 & Model 3* \\
\hline $\begin{array}{l}\text { Maternal depressive symptoms } \\
\text { State income inequality: }\end{array}$ \\
\hline High (Gini >0.430) & $1.6(1.3$ to 2.0$)$ & $1.4(1.1$ to 1.8$)$ & $1.3(1.0$ to 1.7$)$ \\
\hline Medium (Gini 0.416-0.430) & $1.5(1.2$ to 2.0$)$ & $1.5(1.1$ to 1.9$)$ & $1.4(1.1$ to 1.8$)$ \\
\hline Low (Gini $\leqslant 0.415)$ & 1.0 & 1.0 & 1.0 \\
\hline Fifth of distribution of household income: & & \\
\hline Lowest & $5.4(4.0$ to 7.1$)$ & $2.7(1.9$ to 3.9$)$ \\
\hline 2 & & $3.9(2.9$ to 5.2$)$ & $2.3(1.7$ to 3.2$)$ \\
\hline 3 & $2.0(1.5$ to 2.7$)$ & $1.5(1.1$ to 2.0$)$ \\
\hline 4 & $1.5(1.1$ to 2.1$)$ & $1.2(0.9$ to 1.8$)$ \\
\hline Highest & 1.0 & 1.0 \\
\hline
\end{tabular}

Maternal self reported fair/poor health

State income inequality:

\begin{tabular}{lccc}
\hline High (Gini >0.430) & $1.5(1.1$ to 2.1$)$ & $1.3(0.9$ to 1.8$)$ & $0.9(0.7$ to 1.3$)$ \\
\hline Medium (Gini $0.416-0.430)$ & $1.1(0.8$ to 1.6$)$ & $1.0(0.7$ to 1.5$)$ & $0.9(0.6$ to 1.3$)$ \\
\hline Low (Gini $\leqslant 0.415)$ & 1.0 & 1.0 & 1.0 \\
\hline Fifth of distribution of household income: & & $8.5(5.2$ to 13.9$)$ & $3.6(2.0$ to 6.5$)$ \\
\hline Lowest & $6.2(3.8$ to 10.4$)$ & $3.0(1.7$ to 5.2$)$ \\
\hline 2 & $3.2(1.9$ to 5.5$)$ & $2.2(1.2$ to 3.8$)$ \\
\hline 3 & $1.9(1.1$ to 3.5$)$ & $1.6(0.9$ to 2.9$)$ \\
\hline 4 & 1.0 & 1.0 \\
\hline Highest & & & \\
\hline
\end{tabular}

*Adjusted for age, marital status, education, race/ethnicity, and household size. 
Table 3 State income inequality and health outcomes stratified by fifth of distribution of household income*. Figures are odds ratios (95\% confidence intervals)

\begin{tabular}{|c|c|c|c|c|c|}
\hline State income inequality & 1 & 2 & 3 & 4 & 5 \\
\hline \multicolumn{6}{|c|}{ Maternal depressive symptoms } \\
\hline High (Gini >0.430) & 1.7 (1.1 to 2.8$)$ & $1.3(0.8$ to 2.3$)$ & $1.0(0.6$ to 1.6$)$ & $1.4(0.7$ to 2.9$)$ & 1.3 (0.6 to 2.9$)$ \\
\hline Med (Gini 0.416-0.430) & $1.8(1.1$ to 3.0$)$ & 1.3 (0.7 to 2.3$)$ & $1.2(0.7$ to 2.0$)$ & $1.8(0.9$ to 3.8$)$ & $1.1(0.5$ to 2.7$)$ \\
\hline Low (Gini $\leqslant 0.415$ ) & 1.0 & 1.0 & 1.0 & 1.0 & 1.0 \\
\hline \multicolumn{6}{|c|}{ Maternal self reported fair/poor health } \\
\hline High (Gini >0.430) & $1.8(0.9$ to 3.5$)$ & $1.2(0.6$ to 2.5$)$ & 0.7 (0.4 to 1.4$)$ & $0.5(0.2$ to 1.4$)$ & 0.5 (0.1 to 1.5$)$ \\
\hline Med (Gini 0.416-0.430) & $1.8(0.9$ to 3.7$)$ & $1.0(0.5$ to 2.2$)$ & $0.7(0.4$ to 1.5$)$ & $0.6(0.2$ to 1.7$)$ & $0.5(0.1$ to 2.3$)$ \\
\hline Low (Gini $\leqslant 0.415$ ) & 1.0 & 1.0 & 1.0 & 1.0 & 1.0 \\
\hline
\end{tabular}

*Adjusted for age, marital status, education, race/ethnicity, and household size.

Compared with this group, women in the lowest fifth of income distribution who also lived in high inequality states were significantly more likely to have depressive symptoms (3.6, 1.8 to 7.3$)$ but not more likely to be in fair or poor health (2.3, 0.8 to 6.5$)$ after adjustment for covariates. Consistent with the bivariate results in figure 2, certain health advantages could conceivably accrue to women in the top fifth of income distribution in high inequality states, particularly if the mechanisms at work were based more on structural than psychosocial processes. In an exploratory analysis, we used this group (top fifth, high inequality) as the reference group. Compared with this reference group the poorest women in high inequality states were more likely to be in fair or poor health $(4.3,2.0$ to 9.3$)$.

\section{Discussion}

High state income inequality is associated with poorer mental and physical health in women with young children, these associations being most pronounced in women with low incomes. In our study high state income inequality was associated with a $60 \%$ greater risk of depressive symptoms and an $80 \%$ greater risk of fair or poor health among women already substantially worse off because of low household income.

Our findings show the joint influence of high income inequality and low individual income on health. Studies of income inequality that use ecological data have not had the capacity to discern the unique effects of individual income, ${ }^{12}$ while studies of income that use individual level data often fail to examine broader contextual influences. ${ }^{21}{ }^{22}$ Among multilevel studies, only one reported that both income inequality and individual income increase the risk of poor health. Kennedy et al found that high income inequality significantly increased the odds of fair or poor health among those adults already at two to threefold greater risk because of low individual income ${ }^{14}$; however, high income inequality was not associated with adverse health among those in the top income bracket in that study ( $>\$ 35000$ (about $£ 23000)$ ). Fiscella and Franks found no independent effect of income inequality on mortality but did not explore potential interaction effects. ${ }^{13}$ Daley et al found an adverse effect of income inequality on adult mortality among middle income adults but did not report the effects of individual income. $^{8}$ Our results suggest the need for more concerted efforts to explore the combined effects of income inequality and individual income.

The need for a more balanced approach is underscored by the fact that the poorest fifth of families in the United States face both relative and absolute poverty. From 1968 to 1997 their relative income position worsened as the average income of the richest fifth of households rose from 10.2 to 13.6 times their own. ${ }^{23}$ During the same period their mean income remained essentially equal to the US poverty line. Given that the US poverty threshold is not updated for rising standards of living, the living conditions of the poor often reflect absolute deprivation: $11 \%$ report not having enough food to eat, $39 \%$ report living conditions with rats, mice, or cockroaches, and 20\% report not seeking needed medical care. ${ }^{24}{ }^{25}$ Ultimately, the suggestion that relative inequality matters for health should not detract from the continuing importance of absolute deprivation for young families.

\section{Possible mechanisms}

The mechanisms by which income inequality influences maternal mental and physical health are not clear, although several pathways are possible. Consistent with the hypothesis that income inequality is associated with systematic underinvestment in social infrastructure, Kaplan et al found high correlations between income inequality and such indicators as state per capita medical care expenditure and unemployment. ${ }^{5}$ Medical care and labour markets that poorly accommodate women with young children might offer mechanisms by which income inequality operates in this population. More generally, income inequality has been correlated with women's level of political participation (for example, voter turnout, representation in elected office) and economic autonomy (for example, access to health insurance, business ownership) at the state level. ${ }^{26}$ Truncated political and economic opportunities for women in states with high income inequality may ultimately lead to the poor health of women, including low income mothers with young children.

An alternative pathway suggests a mediating role for social isolation and psychosocial processes. Kawachi et al found a strong correlation between income inequality and two measures of social capital: social mistrust and group membership. ${ }^{27}$ Thus, income inequality might increase social isolation, which has been found to be a powerful predictor of poor mental and physical health. ${ }^{28}$ The increased risk of depression among low income women in high inequality states may reflect such increased social isolation. The failure to find a significant association between income inequality and women with higher income, however, suggests caution in generalising the negative effects of income inequality on social cohesion and psychosocial processes; a fraying social fabric may still have its greatest adverse effects among the poor. Importantly, these data cannot discern whether the additional risk of 
depression among low income women in high inequality states is the result of increased social isolation or greater material deprivation, or both.

\section{Interpretation}

Several factors should be considered in the interpretation of these results. Firstly, the data are cross sectional and therefore limit any inferences regarding causation. For example, income and health might both be associated with migration between states. Poor women in good health might be better able to move to states with low inequality and more generous family benefits. Furthermore, poor maternal mental health might lead to lower household income. Studies that used more longitudinal data found limited evidence for income drift. ${ }^{29}$ Further studies examining trends in income inequality, individual income, and health are needed. Secondly, the data on income inequality are not adjusted for taxes, benefits, and household size. Previous work, however, suggests such adjustment of US income data makes little difference in the relation between income inequality and health. ${ }^{30} 31$

Both income inequality and household income seem important for health in women with young children. Income inequality conferred an increased risk of poor mental and physical health, particularly among the poorest women. The finding of such an interaction may help to focus research on the specific mechanisms by which income inequality operates. Historical state-to-state variability in social and economic policy for poor young families, in combination with recent major reforms, may offer an important opportunity for further investigation into these mechanisms.

Funding: Ichiro Kawachi and Bruce P Kennedy are recipients of the RWJF Investigator Awards in Health Policy Research. Ichiro Kawachi is a core member of the MacArthur Foundation Network on Socioeconomic Status and Health.

Competing interests: None declared.

Contributors: RSK conceived the study, analysed the data, and participated in writing the paper. IK, BPK, and PHW assisted with the design, the interpretation of the data, and the editing of the paper. RSK is the guarantor of this paper.

1 Pappas G, Queen S, Hadden W, Fisher G. The increasing disparity in mortality between socioeconomic groups in the United States, 1960 and 1986. N Engl J Med 1993;329:103-15

2 Marmot M, Ryff CD, Bumpass LL, Shipley M, Marks NF. Social inequalities in health: next questions and converging evidence. Soc Sci Med 1997;44:901-10.

3 Wilkinson RG. Income distribution and life expectancy. BMJ 1992;304:165-8

4 Lynch JW, Kaplan GA, Pamuk ER, Cohen RD, Heck KE, Balfour JL, et al. Income inequality and mortality in metropolitan areas of the United States. Am J Public Health 1998;88:1074-80.

5 Kaplan GA, Pamuk ER, Lynch JW, Cohen RD, Balfour JL. Inequality in income and mortality in the United States: analysis of mortality and potential pathways. BMJ 1996;312:999-1003.

6 Kennedy B, I K, Prothrow-Stith D. Income distribution and mortality: cross sectional ecological study of the Robin Hood index in the United States. BMJ 1996;312:1004-7.

7 Wolfson M, Kaplan GA, Lynch JW, Ross N, Backlund E. Relation between income inequality and mortality: empirical demonstration. BMJ 1999;319:953-5.

8 Daly MC, Duncan GJ, Kaplan GA, Lynch JW. Macro-to-micro links in the relation between income inequality and mortality. Milbank $Q$ 1998;76:315-39.

9 Kawachi I, Kennedy BP. Income inequality and health: pathways and mechanisms. Health Services Res 1999;34:215-27.

10 Shapiro I, Greenstein R. The widening income gulf. Washington: Center on Budget and Policy Priorities, 1999.

11 Smeeding TM, Gottschalk P. Cross-national income inequality: How great is it and what can we learn from it? Focus 1998:19;15-29.

12 Gravelle H. How much of the relation between population mortality and unequal distribution of income is a statistical artefact? BMJ 1998;316:382-5.

13 Fiscella K, Franks P. Poverty or income inequality as predictor of mortality: longitudinal cohort study. BMJ 1997;314:1724-8.

\section{What is already known on this topic}

Among the few studies of income inequality, individual income, and health, the two that considered an interaction between income inequality and individual income found mixed results

Though income inequality is commonly thought to operate via psychosocial mechanisms, no previous studies have used individual level data to examine such mental health outcomes

\section{What this study adds}

Women with young children in the lowest fifth of distribution of household income were at substantially higher risk of depression and poor health; the risk being further increased if women also lived in states with high income inequality

Household income and income inequality operated jointly to influence maternal mental and physical health, suggesting a more integrated understanding of the two may help to focus research on the mechanisms at work

14 Kennedy BP, Kawachi I, Glass R, Prothrow-Stith D. Income distribution, socioeconomic status, and self rated health in the United States: multilevel analysis. BMJ 1998;317:917-21.

15 Soobader MJ, LeClere FB. Aggregation and the measurement of income inequality: effects on morbidity. Soc Sci Med 1999;48:733-44.

16 Hill IT. Improving state Medicaid programs for pregnant women and children. Health Care Financing Review 1990:11;75-87.

17 Moffitt R, Ribar D, Wilhelm M. The decline of welfare benefits in the US: the role of wage inequality. J Public Econom 1998;68:421-52.

18 Weissman MM, Sholomskas D, Pottenger M, Prusoff B, Locke B. Assessing depressive symptoms in five psychiatric populations: a validation study. Am J Epidemiol 1977;106:203-14.

19 Idler EL, Benyamini Y. Self-rated health and mortality: a review of twenty-seven community studies. J Health Soc Behav 1997;38:21-37.

20 Kalton G. Introduction to survey sampling. Newbury Park, CA: Sage Publications, 1993.

21 Kaplan GA. People and places: contrasting perspectives on the association between social class and health. Int J Health Serv 1996;26:50719.

22 Yen IH, Kaplan GA. Neighborhood social environment and risk of death multilevel evidence from the Alameda County study. Am J Epidemiol 1999;149:898-907.

23 Weinberg D. A brief look at postwar income inequality. Washington, DC: US Bureau of the Census, 1996.

24 Short K, Shea M. Beyond poverty, extended measures of well-being: 1992. Washington, DC: US Bureau of the Census, 1995.

25 Federman M, Garner T, Short K, Cutter WB, Kiely J, Levine D, et al. What does it mean to be poor in America? Monthly Labor Review 1996;119:3-17.

26 Kawachi I, Kennedy BP, Gupta V, Prothrow-Stith D. Women's status and the health of women and men: a view from the States. Soc Sci Med 1999;48:21-32.

27 Kawachi I, Kennedy BP, Lochner K, Prothrow-Stith D. Social capital, income inequality, and mortality. Am J Public Health 1997;87:1491-8.

28 Berkman LF, Syme SL. Social networks, host resistance, and mortality: a nine-year follow-up study of Alameda County residents. Am J Epidemiol 1979;109:186-204

29 Lynch JW, Kaplan GA, Shema SJ. Cumulative impact of sustained economic hardship on physical, cognitive, psychological, and social functioning. N Engl J Med 1997;337:1889-95.

30 Kaplan GA, Lynch JW, Cohen RD, Balfour JL, Pamuk ER. Income and mortality in the United States. BMJ 1996;313:1207.

31 Kennedy BP, Kawachi I, Prothrow-Stith D. Income and mortality in the United States. BMJ 1996;313:1207.

(Accepted 11 September 2000)

\section{Endpiece}

\section{Enough is enough}

The majority of physicians are surfeited to the point of illness by the reading of journals.

Cited and translated by D A Kronick in A history of scientific and technical periodicals. New York:

The Scarecrow Press,1962:206-7.

Submitted by J H Baron, honorary professorial lecturer, Mount Sinai School of Medicine, New York 